Technical note

\title{
Effects of sulfur and aromatic contents in gasoline on motorcycle emissions
}

\author{
Yung-Chen Yao ${ }^{a}$, Jiun-Horng Tsai ${ }^{\mathrm{a}, \mathrm{b}, *}$, An-Lin Chang ${ }^{\mathrm{a}}$, Fu-Tien Jeng ${ }^{\mathrm{c}}$ \\ a Department of Environmental Engineering, National Cheng Kung University, 1 University Road, Tainan 701, Taiwan, Republic of China \\ ${ }^{\mathrm{b}}$ Sustainable Environment Research Center, National Cheng Kung University, Tainan 701, Taiwan, Republic of China \\ ${ }^{\mathrm{c}}$ Graduated Institutes of Environmental Engineering, National Taiwan University, Taipei 106, Taiwan, Republic of China
}

\section{A R T I C L E I N F O}

\section{Article history:}

Received 13 October 2007

Received in revised form 22 April 2008

Accepted 23 April 2008

\section{Keywords:}

Fuel composition

Four-stroke engine

Exhaust emission

Air toxics

\begin{abstract}
A B S T R A C T
By investigating the effect of sulfur and aromatic contents in gasoline on the criteria pollutant emissions [CO, total hydrocarbons (THCs), and $\mathrm{NOx}$ ] and on air toxics in the exhaust from a non-catalyst four-stroke motorcycle engine, inferences can be made concerning the effect of fuel composition on motorcycle emissions. The fuels were blended with different contents of sulfur (40 and 150 ppmw) and aromatics (20 and 30 vol\%). The data indicate that the sulfur content does not correlate with the emissions of the criteria pollutants from the catalyst free engine. Instead, lowering aromatic content in gasoline reduced the THC emission by over $30 \%$, especially in the cruising test. The NOx emission, however, showed an inverse correlation with the aromatic content in gasoline. While a reduction of aromatic content in gasoline may decrease emissions of benzene and toluene, it will increase the emission of aldehyde. Since the percentage changes of emission factor of THC and air toxics in the motorcycle were larger than those in passenger cars, the benefit of emission reduction due to fuel composition changes in motorcycles may have significant impacts in health risk analysis.
\end{abstract}

(c) 2008 Elsevier Ltd. All rights reserved.

\section{Introduction}

The high mobility, reasonable price, and low fuelconsumption of motorcycles make them a popular onroad vehicle in both urban and suburban areas of many Asian and European countries. The key factors affecting air pollutant emissions from vehicles are engine technology, driver behavior, fuel quality, among others (Pedersen et al., 1980; Westerholm et al., 1992). Changes in gasoline composition can reduce vehicle emissions, because certain gasoline modifications allow engines to perform at their optimum levels.

\footnotetext{
* Corresponding author. Department of Environmental Engineering, National Cheng Kung University, 1 University Road, Tainan 701, Taiwan, Republic of China. Tel.: +886 6 2751084; fax: +886 62083152 .

E-mail address: jhtsai@mail.ncku.edu.tw (J.-H. Tsai).
}

The effects of gasoline composition on vehicle exhaust have been investigated since the early 1990s. The results of Air Quality Improvement Research Program showed that a decrease of sulfur and aromatic contents in gasoline resulted in reductions in CO, THCs (total hydrocarbons), and air toxics emissions (Rutherford et al., 1995). NOx emissions may be influenced by sulfur and olefins content. The results of the European Programme on Emission, Fuels, and Engine Technologies demonstrated that reducing sulfur may reduce $\mathrm{HC}, \mathrm{CO}$ and $\mathrm{NO} x$ emissions, whereas reducing the aromatic content decreased emissions of THC and CO but increased NOx (Goodfellow et al., 1996; McArragher et al., 1999). Several studies indicate that exhaust emissions of $\mathrm{CO}, \mathrm{THC}$, and NOx are related to sulfur and aromatic contents in the gasoline. The amount of air toxic emissions is correlated with aromatic or benzene contents in gasoline (e.g. Perry and Gee, 1995; Schifter et al., 2004). 
However, almost all of the fuel-effect studies have been conducted by using passenger cars and only rarely have studies been focused on motorcycle. With the different engine size and fuel supply systems, it is envisioned that emissions from passenger cars and motorcycles are different. Furthermore, because motorcycles are used primarily as a short distance travel tool and the average travel speed is lower, there is a corresponding increase in pollutant emissions (Tsai et al., 2003).

This study was undertaken to evaluate effects of sulfur and aromatic contents in gasoline on criteria air pollutant emissions (CO, THC, NOx) and five major air toxics from a four-stroke motorcycle engine. Different gasoline mixtures were prepared and used in the engine to investigate the effects of gasoline composition on the exhaust gases in a dynamometer. In order to differentiate the significance effects, a multifactor analysis was conducted. Finally, emission factors of criteria pollutants and of air toxic pollutants were then used to evaluate the effectiveness of emission reduction.

\section{Experimental design}

A factorial matrix of four fuel types was conducted, based on high and low levels of the design variables. Eight fuels were blended by the largest local refinery in Taiwan and were divided into four types; each fuel type contains two fuels and treated as replicate. The actual values of the fuel compositions were 149, 146, 48.5, and 40.5 ppmw for sulfur and 28.6, 22.0, 29.0, and 21.0 vol\% for aromatics in the order of Fuel A, B, C, and D. The octane number was ranged from 95 to 97 for the fuel. A new four-stroke motorcycle engine with displacement of $125 \mathrm{~cm}^{3}$ was chosen as the test one without catalytic converters. A carburetor was used for the fuel supply system. The compression ratio of the engine was 10.1:1.

The experiment of emission test had been conducted at two test modes, i.e., idle and cruising mode, in the present study. The motorcycle engine was linked to the engine dynamometer and tested at a cold-start mode under different rotation speeds, which were $1718 \pm 105 \mathrm{rpm}$, $4828 \pm 4 \mathrm{rpm}$, and $5763 \pm 45 \mathrm{rpm}$ for idle, mid-speed, and high-speed tests, respectively. The latter two rotation speeds were treated as a cruising test mode. According to our results of mass emission $\left(\mathrm{gtest}^{-1}\right.$ ) based on the Economic Commission for Europe (ECE) cycle (data are not published), the cruising mode produced relatively high percentages of the criteria air pollutants $(50 \%$ for THC, $57 \%$ for $\mathrm{CO}$, and $42 \%$ for NOx) for the non-catalyst four-stroke motorcycle, followed by deceleration (16$33 \%$ ), acceleration (14-20\%), and idle (10-12\%). Therefore, over $52-67 \%$ of mass emissions were attributed from the mode of cruising and idle. Tsai et al. (2000) also shows that over $40 \%$ of VOC emission were attributed from the modes of idle and cruising. Base on these reasons, the sample was collected for the idle and cruising modes (steady-state modes) in our study. Also, due to the limitation of our equipment, the operation for accelerations and decelerations cannot be stable.

Exhaust gases were connected to a stainless chamber and filter; criteria pollutants were analyzed simultaneously by an in-situ monitor (MEGA 300 Tail Gas Analyzer, Mastek Technologies) during 5 min operating time. Four tests of the commercial gasoline were conducted to evaluate the test reproducibility. The average values of reproducibility for CO, THC, and NOx were 97, 92 and 86\%, respectively, for the idle mode and 89,84 and $86 \%$ for the cruising mode.

Air toxics species in the sample gas were quantified by a gas chromatography/mass spectrometer (Varian Star 3600 GC plus with a Varian Saturn 2000 MS). Carbonyl components in the exhaust were collected by silica gel cartridges with 2,4-dinitrophenylhydrazine, extracted with acetonitrile and were analyzed by high performance liquid chromatography (Hewlett Packard 1100 series) equipped with an ultraviolet-visible detector. The method detection limits for target air toxic pollutants were $2.1 \mu \mathrm{g} \mathrm{m}^{-3} \quad$ (benzene), $\quad 3.8 \mu \mathrm{g} \mathrm{m}^{-3} \quad$ (1,3-butadiene), $5.5 \mu \mathrm{g} \mathrm{m}^{-3}$ (toluene), $9.7 \mu \mathrm{g} \mathrm{m}^{-3}$ (formaldehyde) and $24.1 \mathrm{~g} \mathrm{~m} \mathrm{~m}^{-3}$ (acetaldehyde). Except for toluene, all the selected air toxics are carcinogenic.

The emission factors of various pollutants were assessed with the volume of the exhaust, the exhaust mass, and the fuel consumption in one test cycle as mentioned in Tsai et al. (2003). Percentage changes of emission factor were calculated by comparing the mean emission data of the respective fuel content. In addition, substantiating the effects of fuel composition on the pollutant emission, the statistical significance between the exhaust pollutant level and the fuel compositions was also evaluated. The 95\% statistical confidence level was used for all comparisons.

\section{Results and discussion}

\subsection{Effects of fuel compositions on exhaust $\mathrm{CO}, \mathrm{THC}$, and NOx emissions in the idle test}

The effects of fuel sulfur and aromatic contents on $\mathrm{CO}$, THC, and NOx emissions in the idle mode are illustrated in Fig. 1a. The CO emission factors ranged from 533 to $581 \mathrm{~g} \mathrm{~L}^{-1}$-fuel. The variance, calculated by the estimated emissions for the high and the low sulfur content gasoline, changed slightly by $-4 \%$ in $\mathrm{CO}$ emissions while reducing sulfur content (from 150 to $40 \mathrm{ppmw}$ ) in the high aromatic content (30 vol\%) fuel; however, there is no change in the low aromatic (20 vol\%) fuel. The THC emission factors ranged from 29.9 to $31.9 \mathrm{~g} \mathrm{~L}^{-1}$-fuel. Decreasing the sulfur content at high aromatic content fuel showed that the variance in THC emissions was increased by $7 \%$. Because the data of THC was unstable during the idle test of Fuel B (high sulfur and low aromatic contents), the test results for that low aromatic content fuels were not analyzed. Comparing to the results of the fuel compositions in regard to their sulfur content reveals a $-14 \%\left(0.48-0.41 \mathrm{~g} \mathrm{~L}^{-1}\right.$-fuel) and $-12 \%\left(0.54-0.48 \mathrm{~g} \mathrm{~L}^{-1}\right.$-fuel $)$ variation on the NOx emission for the high and low aromatic content test fuels, respectively, in the idle test; thus the emission variances that caused by reduced sulfur content in fuel were similar. The test data show that there was no significant impact, compute by using two-way analysis of variance (two-way ANOVA), between the fuel sulfur content and the $\mathrm{CO}$ and NOx emissions. Since the present motorcycle had no 

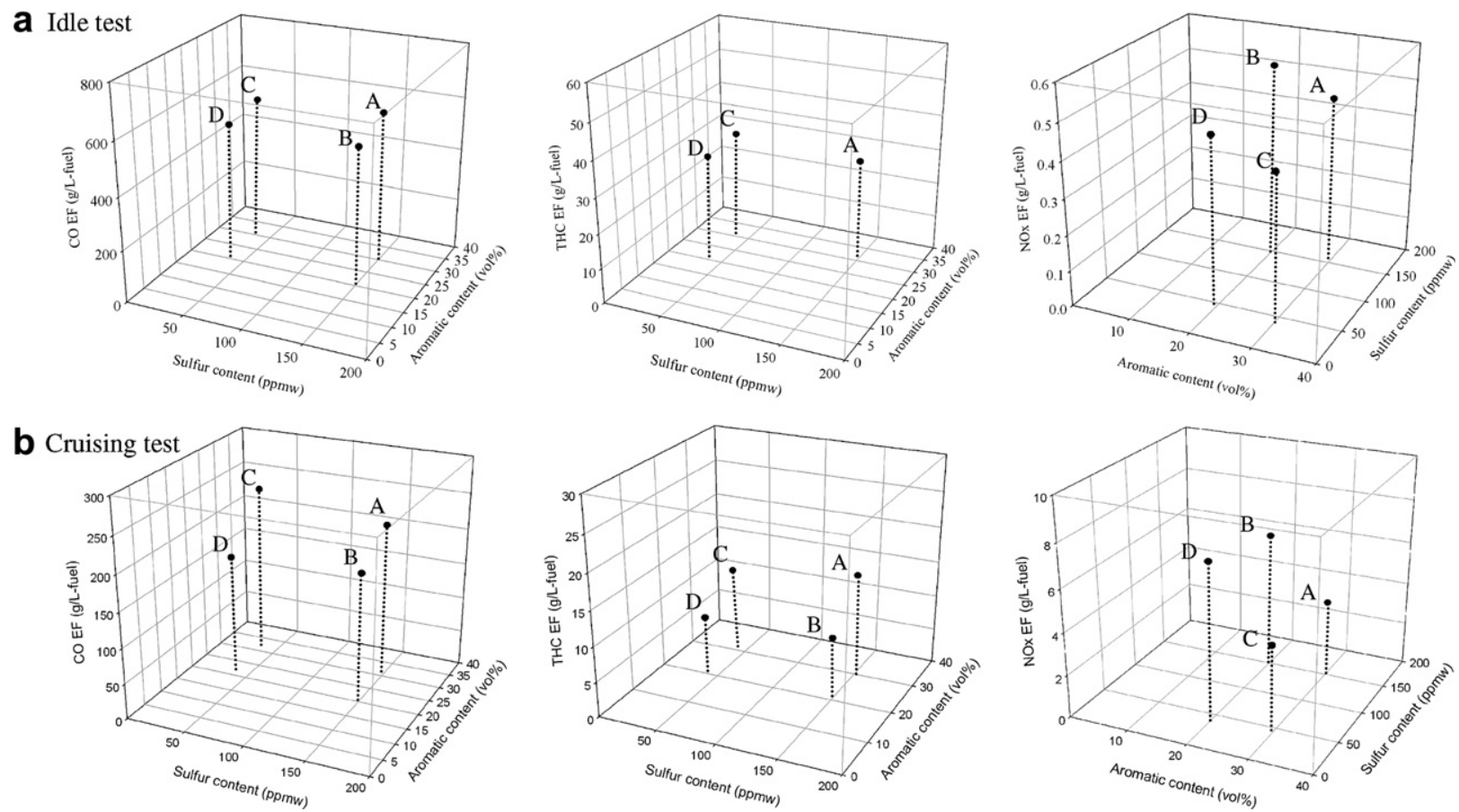

Fig. 1. Effects of reducing fuel sulfur and aromatic contents on CO, THC, and NOx emissions in (a) the idle and (b) the cruising test. (A, B, C, and D represent the test fuels.).

catalytic converter, we presume that the sulfur poses no significant reduction on criteria emission as was also reported with non-catalyst cars (MacKinven and Hublin, 1996).

The data show that decreasing aromatics in gasoline (from 30 to $20 \mathrm{vol} \%$ ) decreases exhaust $\mathrm{CO}$ and THC emissions slightly by $2-8 \%$ (Fig. 1a). The low aromatic content test fuels, however, showed a higher NOx emission than those with a high aromatic level. The variance is 14 and $16 \%$, respectively, for the fuels with same high and low level sulfur content. The result of statistical analysis indicates no significant effect on NOx from aromatics content in gasoline. The fuel aromatic content influence on NOx emission is attributed by following reasons, catalyst conversion efficiency and spark retardation, from the pervious car studies (Goodfellow et al., 1996; Schuetzle et al., 1994). The test motorcycle in our study did not equip catalyst converter, we presume that spark retardation is the probable reason for low NOx emissions observed in the present study. The spark retardation due to high aromatic content may reduce engine temperatures and result in decreases in exhaust $\mathrm{NO} x$ (Schuetzle et al., 1994), the same as observed in our case.

\subsection{Effects of fuel compositions on exhaust $\mathrm{CO}, \mathrm{THC}$, and NOx emissions in the cruising test}

Fig. 1b presents the effects of sulfur and aromatic contents on the criteria emissions for motorcycle in the cruising mode. The emission factors ranged from 175 to $244 \mathrm{~g} \mathrm{~L}^{-1}$-fuel, 8.5 to $14.7 \mathrm{~g} \mathrm{~L}^{-1}$-fuel, and 3.6 to $7.3 \mathrm{~g} \mathrm{~L}^{-1}$. fuel for CO, THC, and NOx, respectively, in the cruising mode. The test results indicated that the $\mathrm{CO}$ and $\mathrm{THC}$ emission factors were lower in the cruising mode than those in the idle mode, except for NOx. High emission of NOx is due to higher combustion temperature because of high speed in cruising mode (Jia et al., 2005).

Using the test fuel with high aromatic content (30 vol\%), when sulfur content was tested at the two levels 150 and 40 ppmw, CO emissions decreased $11 \%$. Using the test fuel with low aromatic content (20 vol\%), when sulfur content was tested at the two levels 150 and 40 ppmw, CO emissions increased $5 \%$. On the other hand, the variances for THC emissions were $-16 \%$ and $-7 \%$ while reducing fuel sulfur content. The data show that the low sulfur content test fuels increase NOx emission, regardless whether in the high and low aromatic content test fuel.

A reduction in aromatic content (30-20 vol\%) in the gasoline may lead to lower $\mathrm{CO}$ and THC emissions in the test motorcycle (Fig. 1b). The decreased percentages for CO emissions were 17\% (in high sulfur content fuel) and $28 \%$ (in low sulfur content fuel), and were 38 and $31 \%$ for THC emissions. The findings of the effects of gasoline aromatic content on the $\mathrm{CO}$ and THC emissions are in agreement with the previous studies for cars (Goodfellow et al., 1996; Schifter et al., 2004). Reducing the fuel aromatics, however, increases the NOx emission significantly (from 3.6 to $6.4 \mathrm{~g} \mathrm{~L}^{-1}$-fuel and 4.2 to $7.3 \mathrm{~g} \mathrm{~L}^{-1}$-fuel, Fig. 1b). In brief, the observations of the effect of gasoline aromatic content on the criteria emissions in the cruising test in the present study showed that fuel aromatic content reduction may lower the CO and THC emission. In contrast, the fuel aromatic content poses significant increasing effect on NOx emission in the non-catalyst motorcycle. 
Above all the experimental data indicated that the criteria pollutants emissions from a four-stroke motorcycle engine are more influenced by aromatic content, and not sulfur content, in gasoline.

\subsection{Effects of fuel aromatic on exhaust air toxics emission}

In all test fuels, toluene and benzene represent the highest emissions among the target air toxics (Table 1). A decrease in aromatic content (from 30 to 20 vol\%) lowered toluene and benzene emissions by 48 and $17 \%$ in the idle test, and 41 and 30\% in the cruising test, respectively. Goodfellow et al. (1996) have reported that the increased benzene and toluene exhaust emissions for higher aromatic fuel is caused by dealkylation during the combustion process. As for 1,3-butadiene and formaldehyde, the emission factors showed similar results with low or high aromatic fuel used. The 1,3-butadiene is mainly produced from olefins and naphthene content and is not influenced by aromatics (Zervas et al., 1999); the results of motorcycle engine are in agreement with previous car studies.

For acetaldehyde, the data, on the other hand, show increased emissions when low aromatic fuel was used. Acetaldehyde is not present in the gasoline; it is the incomplete combustion products of fuel (Chevron Products Company, 2003). Decreasing gasoline aromatic content may require additional paraffin content. The higher aldehyde emissions may be the result of the increased fraction of the paraffin (Schuetzle et al., 1994; MacKinven and Hublin, 1996).

Table 2 summarizes the effects of gasoline compositions on the exhaust emissions; data for cars are also included for comparison. Benzene and toluene were presented in great amounts in motorcycle exhaust, thus, any step for reducing their emission should be taken. Although a reduction of fuel aromatics may increase aldehyde emissions, in terms of toxics emission control, a low aromatic content in gasoline may still contribute to an overall diminution in hazardous

Table 1

Effects of reducing fuel aromatics content from 30 to $20 \mathrm{vol} \%$ on air toxics emissions

\begin{tabular}{llcc}
\hline Pollutants & Aromatics (vol\%) $^{\text {a }}$ & \multicolumn{2}{c}{$\begin{array}{l}\text { Emission factor } \\
\text { (mg L }\end{array}$} \\
\cline { 3 - 4 } & & Idle & Cruising \\
\hline Benzene & 30 & 918 & 303 \\
& 20 & -164 & 211 \\
& Variation (\%) & 353 & -30 \\
1,3-Butadiene & 30 & 358 & 8 \\
& 20 & 1.4 & -8 \\
Toluene & Variation (\%) & 1011 & 648 \\
& 30 & 529 & 379 \\
& 20 & -48 & -41 \\
Formaldehyde & Variation (\%) & 219 & 126 \\
& 30 & 228 & 129 \\
& 20 & 4 & 2 \\
Acetaldehyde & Variation (\%) & 64 & 84 \\
& 30 & 88 & 108 \\
& 20 & 27 & 22 \\
\hline
\end{tabular}

${ }^{a}$ The fuel with 30 vol\% aromatic content is Fuel A and C, and 20 vol\% aromatic content is Fuel B and D.

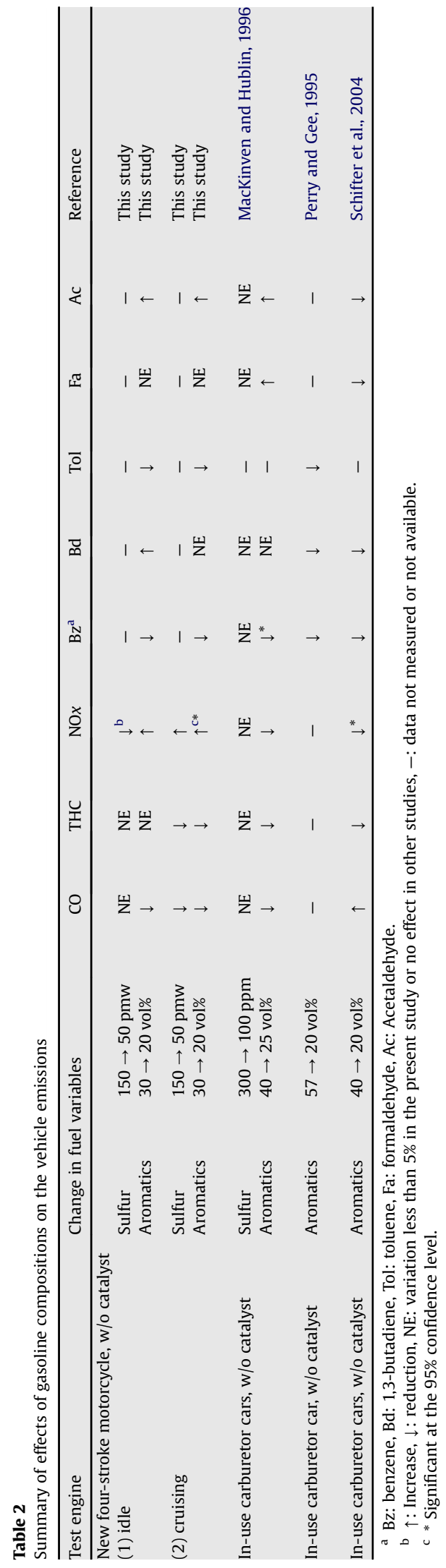


risk. Because the emission factors of motorcycles are quite higher than those in cars; therefore, the benefit of emission reduction due to fuel composition changes in motorcycles may have significant impacts in air toxics in urban area.

\section{Conclusions}

This paper presents the correlation between fuel compositions and air pollutant emissions (CO, THCs, NOx and air toxics) of a non-catalyst four-stroke motorcycle engine in the idle and the cruising test mode. A reduction in fuel sulfur content from 150 to $40 \mathrm{ppmw}$ showed no significant improvement in $\mathrm{CO}$, THC or NOx emissions. A reduction in fuel aromatic content from 30 to $20 \mathrm{vol} \%$ decreases THC emissions and increases NOx emissions. These results demonstrate that the criteria pollutants emissions are influenced by fuel aromatic content more than sulfur content.

For air toxics emissions, a reduction in fuel aromatic content from 30 to $20 \mathrm{vol} \%$ decrease benzene and toluene emissions, but increased the aldehyde emissions. Since the percentage changes of emission factors of air toxics in the motorcycle were larger than those in cars, the benefit of emission reduction due to fuel composition changes in motorcycles may have significant impacts in health risk analysis.

\section{Acknowledgments}

This research was supported by grants from the National Science Council and the Environmental Protection Administration, Taiwan, Republic of China (NSC 94-EPA-Z-006006 and NSC 95-2221-E-006-172-MY3).

\section{References}

Goodfellow, C.L., Gorese, R.A., Hawkins, M.J., McArragher, J.S., 1996 European Programme on Emission, Fuels and Engine Technologies -
Gasoline Aromatics/E100 Study. SAE Paper No. 961072. Society of Automotive Engineers, Warrendale, PA.

Jia, L.W., Shen, M.Q. Wang J. Lin, M.Q, 2005. Influence of ethanol-gasoline blended fuel on emission characteristics from a four-stroke motorcycle engine. Journal of Hazardous Materials 123 (1-3), 29-34.

MacKinven, R., Hublin, M., 1996. European Programme on Emissions, Fuels and Engine Technologies - Objectives and Design. SAE Paper No. 961065. Society of Automotive Engineers, Warrendale, PA.

McArragher, J.S., Becker, R.F., Bennett, P.J., Claus, G., Graham, J., Lang, G., van Leeuwen, C.J., Rickeard, D., Schuermann, F., Heinze, P., 1999. Fuel Quality, Vehicle Technology and Their Interactions. Report No. 99/55. CONCAWE, Brussels.

Pedersen, P.S., Ingwersen, J., Nielsen, T., Larsen, E., 1980. Effect of fuel, lubrication, and engine operating parameters on emissions of polycyclic aromatic hydrocarbons. Environmental Science \& Technology 14 (1), 71-79.

Perry, R., Gee, I.L., 1995. Vehicle emissions in relation to fuel composition. Science of the Total Environment 169 (1-3), 149-156.

Rutherford, J.A., Koehl, W.J., Benson, J.D., Burns, V.R., Hochhauser, A.M. Knepper, J.C., Leppard, W.R., Painter, L.J., Rapp, L.A., Roppon, B., Reuter, R.M., 1995. Effects of Gasoline Properties on Emissions of Current and Future Vehicles-T50, T90, and Sulfur Effects-Auto/Oil Air Quality Improvement Research Program. SAE Paper No. 952510. Society of Automotive Engineers, Warrendale, PA.

Schifter, I., Diaz, L., Vera, M., Guzman, E., Lopez-Salinas, E., 2004. Fuel formulation and vehicle exhaust emissions in Mexico. Fuel 83 (14-15), 2065-2074.

Schuetzle, D., Siegl, W.O., Jensen, T.E., Dearth, M.A., Kaiser, E.W., Gorse, R., Kreucher, W., Kulik, E., 1994. The relationship between gasoline composition and vehicle hydrocarbon emissions: a review of current studies and future research needs. Environmental Health Perspectives 102 (Suppl. 4), 3-12.

Tsai, J.H., Hsu, Y.C., Weng, H.C., Lin, W.Y., Jeng, F.T., 2000. Air pollutant emission factors from new and in-use motorcycles. Atmospheric Environment 34 (28), 4747-4754.

Tsai, J.H., Chiang, H.L., Hsu, Y.C., Weng, H.C., Yang, C.Y., 2003. The speciation of volatile organic compounds (VOCs) from motorcycle engine exhaust at different running modes. Atmospheric Environment 37 (18), 2485-2496.

Westerholm, R., Almen, J., Li, H., Rannug, U., Rosen, A., 1992. Exhaust emissions from gasoline-fuelled light duty vehicles operated in different driving conditions: a chemical and biological characterization. Atmospheric Environment 26B (1), 19-89.

Zervas, E., Montagne, X., Lahaye, J., 1999. The influence of gasoline formulation on specific pollutant emissions. Journal of the Air \& Waste Management Association 49 (11), 1304-1314. 